\title{
On the Relation between Creative Treason and Faithfulness, Expressiveness and Elegance
}

\author{
Peina Zhuang \\ Foreign Language Department, Yinxing Hospitality Management College of CUIT, China; \\ College of Journalism and Literature, Sichuan University, China
}

\begin{abstract}
This paper discusses the relation between "creative treason" and "faithfulness, expressiveness and elegance" based on the concept of "creative treason" with a view to pointing out that the categorization of any deformation or distortion in translation into "creative treason" is overstated, placing the term "creative treason" in a trend of infinity, whether on its meaning or scope. Thus, this thesis holds that "faithfulness, expressiveness and elegance" in this aspect could serve as a delimiting boundary for the term "creative treason", or more concretely, "faithfulness" as the basis and "expressiveness and elegance" as the objective reality. The essence of "creative treason" can be defined as variability at the lingual and cultural level in cross language translation and the objective "deviation" from the source text on the basis of maintaining "faithfulness".
\end{abstract}

Index Terms — creative treason, faithfulness, expressiveness, elegance, variability

\section{INTRODUCTION}

Eugene Nida holds that translation means translating meaning, which has been agreed by many domestic scholars who think that in talking of "creative treason", there should be some 'extent'. That is, "the means of transferring meaning in translation should come after 'the meaning' itself and treason of meaning counteracts the translators' deadline, which should be prohibited." (Ni, 2004, p.92) A translator seeks to achieve the perfect transfer of meaning by way of change of linguistic forms. But the meaning of language is composed of signifier and signified. Thus, it is not difficult to understand why Robert Escarpit holds that translation is "creative treason": "To hold that translation is treason is due to the fact that the original work is put into an unexpected reference system (referring to language); and that translation is also creative means that the original work is given a new outlook and comes into contact with new readers; translation gives the original work a second life". (1987, p.137) The change in linguistic forms and the ambiguity and complexity may give rise to "deviation" from the original meaning. But a translator can, by way of creative treason, give the original work a new look in compensating at the linguistic or cultural level.

The introduction of the term into literary translation by Xie Tianzhen has aroused wide controversy. Some scholar regard the term as rule as exemplified by "the focus on the discussion of the term is not an issue of "how we should translate', but as mentioned before, is a matter of uncovering the essence of translation and confronting the objective phenomenon in translation" (Xie, 2012, p.37). Some other scholars deem it as a strategy or phenomenon, such as "though sometimes creative treason leads to 'treason' at the linguistic level or omission and amplification in content, it is the indispensable strategy after thorough thoughts of the translator" (Huang, 2013, p.91). Different views hover around on the discussion of the term. "Any concept, if it is to be understood, must have some prescriptive features so as to control the infinity of its meaning, thus avoiding the danger of decomposing itself" (Liu, 2006, p.132). This is also applicable to the term. The feature of the term must be clarified in order to identify the academic position of the term. This thesis summarizes the feature as being universal, conventional, prescriptive and descriptive. It is universal since creative treason exists in every stage of translation, visible or invisible. A translator's 'prejudice' determines his historicity of understanding, which is by no means infinite, but is confined by the original work. The original one is the basis for creative treason. It is conventional in that the "deviation" in creative treason should conform to the norm of the original language, target language and translation under different backgrounds in the case of difference between signifier and signified in different cultures. Those who deem the term as a phenomenon or rule start from the feature of being descriptive. Thus, it is improper to classify it just as phenomenon, rule or method. The features of creative treason demonstrate that it is both dynamic and static; both a process and a result; and both a phenomenon and a strategy. The key here lies in the perspective. Escarpit's view of creative treason does not elaborate on the definition of the term, nor does it fix the term at the level of phenomenon, method or rule. Thus, one could start discussion from a certain level but not in a position to dispel other levels or aspects. But creative treason is not a "black box" into which one can put everything. There should be some "Golden Hoop" to control the spread of its meaning, which is Yanfu's "faithfulness, expressiveness and elegance" in translation.

\section{Relation BETWEen the Two Terms}


Yanfu once put forward the translation norm of faithfulness, expressiveness and elegance, which can also be seen as the difficulty in translation. "Faithfulness" means "one should be 'honest' to the original work" (Lin, 2000, p.2), that is, the meaning of the translated version should stand true to the original work. 'It is difficult to achieve 'faithfulness'. But 'faithfulness' achieved without 'expressiveness' can not make an acceptable translation; Thus, 'expressiveness' should also be valued" (Editing Board of Translation Newsletter, 1984, p.6). Yan only mentions "faithfulness" twice, not because it is unimportant, but it is self-evident for a translator and is the prerequisite in translation. "Faithfulness" means being 'honest' both at the level of form and content. In other words, it is the prescriptive requirement of creative treason. In the poly-system composed of the original and target work, the former stands at the center while the latter is a new elucidation on the basis of the former, which may explain why every translation is a different version of the original work and that so as far as the translation of Chinese Classics goes, “'Other' translations can never be finished, only laid aside. They can always be improved" (Newmark, 2001, p.140) in one aspect or another since the reproduction of these three elements are at most times incompatible in translation, calling for retranslation and the coexistence of different foreign versions of the same work. Just as the fusion of horizon in the process of understanding, a translator could only achieve the "fusion" after he enters into the horizon of the original work. "While emphasizing the horizon of the original work, we can not neglect that of the original work. No matter how wild the imagination of the translator is, it can not reach beyond the original work" (Cao, 2005, p.197). Every translated version is, in its extent, the fusion of horizon of the original work. Thus, "there is honest element even in the most deviated version" (Dong, 2006, p.5). Thus, "faithfulness" is the basis and prerequisite of creative treason.

But Yanfu also realizes that one can not achieve both the faithfulness in level of form and content: "a translation should extract the meaning from the original work though sometimes with the unavoidable change of the form" (Editing Board of Translation Newsletter, 1984, p.6). In such case, the translator could only choose one, which is being faithful to content by adjusting the forms in accordance with the writing style and norm of target language and culture, such as the sentence from Caigen Tan, a Chinese work of axioms:

ST: 饥则附, 饱则㲽, 燠则趋, 寒则弃, 人情通患也。

TT: When we are hungry we seek relief from others. When we have full stomachs we shun others. If there is a warm shelter, we all flock to it. If there is a freezing shanty, we all turn our backs on it. This is a common flaw in human nature.

In the above example, the heterogeneity between the Chinese and western languages demonstrates that a translator could also achieve "faithfulness" in the level of content. For instance, the above sentence has no subject, object and no conjunction between each part of the sentence. The translator here adds the subjects "we", "there is" and "this is" to make the version grammatically acceptable in English, which, unlike the ancient Chinese, must have a subject in the sentence. What's more, the English version also divides the original sentence into four parts by adding some connectives for the understanding of ancient Chinese could to a large extent rely on the inner logics of the sentence without the clues of connectives, while semantic relation in English is more obvious in surface. Some scholar points out that "the Chinese grammar is relatively free without the constraint of tense, passive and active voice, etc.......there is little emphasis on the connectives; thus, every element in a sentence, such as subject, verb and object, etc., can be omitted or reversed" (Ye, 1997, p.115). Chinese is a language of parataxis and English hypotaxis. Western languages are characterized by being accurate in wording while the Chinese characters are highly condensed, using the least words to convey the most meanings, leading to ambiguities and uncertainties, even in the case of philosophical works, let alone literary ones. Thus, it sets great store by the readers' empathy with the text, seeing through the shell of language to grasp the deep meanings therein. It puts much stress on those from a different cultural background for even a native speaker sometimes can not understand classical Chinese well since modern vernacular Chinese are quite different from the classical Chinese in many aspects. As an English speaker, though he can rely on other references to understand the meaning of the original, the translator can not get rid of expression habit from his mother tongue. Language as part of culture is so deeply rooted in himself that he is always under the influence of it, consciously or unconsciously. Thus, the brevity displayed in the original work is somewhat impaired, which makes the "transfer of meaning" possible and similar cases could be found in other translation of Chinese work into English, the ancient classics in particular, such as the following rendition of “楼上看山, 城头看雪, 灯前看月, 舟中看霞, 月下看美人, 另是一番情境” into: “Things give you a different mood and impression when looked at from a particular place: such as hills seen from atower, snow seen from the top of a citywall, the moon seen in lamplight, river haze seen from aboat, and pretty woman seen in the Moonlisht".

Such "treason", in its essence, is the variation in cross-language translation. The Variation Theory, first proposed by Cao Shunqing in 2005 Study on Comparative Literature can be classified into variation in the level of language, national image, literary text and culture, etc. Literary variation has long existed, including the synchronic and diachronic angle. The latter refers to the changes in the meaning of language due to the times, such as the meaning of "wife" as compared with the meaning in ancient Chinese. Variation at the synchronic level is rather pronounced in cross-language and cultural literary exchange and displays the tension of collision therein. Translation serves as a good example in this regard and the variation in translation is the result of such variation since in cross-language translation, when form and content can not be both transferred, the former will be given up in favor of the latter, thus causing variation at the level of linguistic forms. But even the give up of transferring forms can not guarantee the complete 
transfer of content. In chapter three of "Migrating Variation" in his book Poetics Dialogue between East and West, Wang Xiaolu elaborates the different understandings of the ancient Chinese literary theories by the English world by way of translation, pointing out the role of "trapping" by the language in the process of communication. The view of translation being an impossible task by the Germany linguist William Humboldt may be go too far, but it is reasonable in some extent, especially in the case of Sino-English translation, which is further testified by "five losses and three difficulties" in translation by Dao An, the famous monk in Tang Dynasty in ancient China. "Treason" at the level of language is not so deep as compared with that at the level of culture in the form of "culture filtering", causing literary misreading sometimes.

Cultural filtering is a hotspot in nowadays' translation studies since the cultural turn in this field. The book Constructing Cultures-Essays on Literary Translation by Susan Bassnett and André Lefevere signifies the advent of the cultural turn in translation studies, which greatly overturns the center in translation studies since the 'linguistic turn' and comes to emphasize the cultural aspect of translation which gives rise to various translation theories, for instance the feminism school, the post-colonial school and so on and the definition of translation has ever since then undergone profound changes. And many western translation theorists and experts come up with their own distinguished terms to refer to translation among which the following ones are most widely quoted: intercultural communication by Christiane Nord; intercultural cooperation by Holz-Manttari; acculturation by Lefevere, etc. And this turn has also largely influenced the domestic translation studies. Recent years have seen the publication of many books on this aspect. Guo Jianzhong's Culture and Translation is just one of them where the author of the book collected some representative articles on translation studies from the perspective of cultural studies that largely promote the cultural studies in translation. For instance, Lv Jun, a famous domestic scholar on translation holds that translation is an activity of social cross-cultural and inter-lingual communication and exchange (2001, p.1-2). So from the above review of the cultural turn in translation studies, one can see that translation studies has been adjusted from the prescriptive study to the descriptive study during which the translator's role has been greatly recognized, for it is the translator's subjectivity that plays an essential role in dealing with those cultural factors in translation, especially in literary translation and also during which, the phenomenon of creative treason is pushed forward on the stage for wide discussion in recent years.

It has for centuries been taken for granted that translation merely takes place between languages. This assumption unleashed the word vs. sense debate in traditional theory and lies at the heart of the concept of equivalence. Such concept no longer prevails with the development of translation studies since it has become generally known that translations are no longer produced in a vacuum. And cultural filtering is an important phenomenon in the process and has been widely discussed and explored. It refers to the process of selecting, transforming, transplanting and infiltrating of information by recipients from different cultural background and tradition. It is also a reaction of the recipient towards the influence from the original source by way of creative reception (Cao, 2002, p.184) and can be manifested in reproduction of the musicality, artistics and culture-loaded words etc., in translation. For instance, a translator has to face the great difference between Sanskrit and Chinese, whether lingual or cultural in the initial introduction of Buddhism into China, such as that "the rules and its view on life and death of Buddhism are incompatible with the ethics guidelines of the Chinese emperors and it is preachers' task to coordinate there contradictions" (Zhou, 2003, p.162). For instance, in the view of Buddhism, body of human beings is composed of earth, water, fire and wind. But An Shih-kao renders it into "qi" instead of the four elements in Anapanasati Sutta since "qi" is often used in Chinese culture to understand the universe and various phenomena. The concept of "yuanqi" (primordial qi) can be traced back to the end of Western Zhou Dynasty as exemplified by "the qi of heaven and earth, if in disorder, will lead to chaos among people and even cause earthquake." "Qi" here is physical. But it was further developed by Daoism in the Warring States period. Lao Zi holds that the utmost category "Dao" generates yin and yang which give birth to everything in universe. Zhuang $\mathrm{Zi}$ further develops the concept on the basis of Lao $\mathrm{Zi}$ and holds that the concentration of "qi" gives birth to human beings. Thus, an obvious "yuanqi" view of life and death. Wang Chong, a philosopher in Eastern Han Dynasty, is another representative of "yuanqi" and conducts deep analysis of "qi" which is the basis for human life. Thus, it is not difficult for one to understand the rendition into "qi" in the above example. Yue Daiyun once said that "the contact of two cultures, due to their differences, will inevitably give rise to misreading which is a way of interpreting another culture from one's own cultural tradition and mentality" (1995, p.110).

Such "treason" is widely accepted by those engaged in Buddhist script translation, displaying the efforts by the translators in adapting Buddhism to Chinese tradition, paving the path for the sinicization of Buddhism. Creative treason in this stage mainly involves the introduction and fusion of Buddhism into China. With its further development, it may stimulate creative writing. A good example in this regard is Fumu Enzhong Jing (Script of Parents' Favor to Children) in Tang Dynasty. Wang Kefei has also investigated the great influence of Buddhist literature translation on Chinese literature (1997, p.27-43). "Treason" of this kind also demonstrates the consideration of the readers' expected horizon by the translator since after all, only after the translated version is read can one say the process of translation is done, which is very pronounced in Yanfu's "elegance".

"The Book of Changes has the following saying that one should display his real intentions in his writing. Confucius once also said that one's wording should be expressive and that without elegance one's work can exert little influence. The above three requirement should be the norm both for writing and translation. Thus, besides 'faithfulness' and 'expressiveness', 'elegance' should also be strived not only for wide dissemination of the work but also for the refined 
style therein, which could be better realized by use of the ancient Chinese diction and grammar" (Editing Board of Translation Newsletter, 1984, p.6). And Yanfu holds the similar view that besides "faithfulness" and "expressiveness", "elegance" should also be achieved if possible so that the translated version could go a long way. In this connection, He has expanded his horizon from the narrow sense of translation to the broad sense of translation, one including the reader and the receiving environment. "Faithfulness" and "expressiveness" aims to realize the textual purpose while "elegance" seeks to achieve the non-textual purpose by way of creative treason, that is, to attract the attention of the literati at that time. "Elegance" means to use the ancient Chinese diction and grammar with the purpose of the literati's taste since "he realize he must coat the new thought of the books with a layer of 'sugar', which is the ancient Chinese wording; 'Elegance' is his trick to attract their attention" (Wang, 1989, p.41). The "chief translator" of modern and contemporary Chinese literature, Howard Goldblatt holds that the great difficulty in translation lies not in understanding the original text but in one's proficiency of the target language, which shows the reason for the cultural and lingual variation by the translator in consideration of the expected horizon of the reader.

\section{CONCLUSION}

If one regards "faithfulness, expressiveness and elegance" as the Golden Hoop of creative treason, the essence of the term is variation, such as at the level of language and culture. The subjectivity of the translator, such as the learning accomplishment, individual horizon and ideological standing, etc., has a great role in the process. Thus, the very essence of creative treason is variability and the phenomenon in creative treason is variation at the level of cross-language variation. Here, the paper will mention more about the Variation Theory so that better understandings about the term could be achieved. The phenomenon of "variation" has long existed since the sinicization of Buddhism as has been explained before. The Chinese Chan Buddhism can be seen as a good example since it is complex form of varied religion from Buddhism examined from the perspective of embryology. And actually many scholars, domestic and abroad have come to notice it such as Wang Guowei who has investigated the Sino-western mutual elucidation, Yan Shaodang in his endeavor in research of literary variation of Japanese literature and the western scholar Edward Said in his work on Travelling Theory, to name just a few. "The proposal of Variation Theory first came up in the third chapter "Literary Variation" in Study of Comparative Literature, which is divided into six subparts, namely, Translatology, Iamgologie, Reception Studies, Thematology, Genology and Cultural Filtering and Misreading, but not includes the investigation of the naming from the theoretical level" (Cao \& Zhuang, 2014, p.52). And more information about this theory could be found in works such as Study of Comparative Literature (2005), The Variation Theory of Comparative Literature (2014), Lecturing on Variation Theory of Comparative Literature (yet published) by Cao Shunqing and other papers illustrating the theory. And the paper here is supportive of the view to judge the essence of creative treason from the perspective of this theory.

But Yanfu's "faithfulness, expressiveness and elegance" could control the endless spread of the term's scope in that "faithfulness" is the basis while "expressiveness and elegance" is the objective ground for creative treason. The proportion of creative treason in any quality translation is rather small and is the choice of the translator in case of the huge language and cultural gap. In addition, the adoption of "faithfulness, expressiveness and elegance" to constrain the scope of creative treason could also turn the trend of overcorrection of creative treason by some scholars who thinks that "the textual meaning could be determined by elements such as logical relations, rhetorical speeches, register and context, etc."(Zhao, 2005, p.41). But translation after all is not carried out in vacuum and it is not proper to hold a thorough scientific view of translation, which goes too far and equals the sense of regarding any translation as creative treason.

\section{REFERENCES}

[1] Cao, Shunqing eds. (2005). Study of Comparative Literature. Chengdu: Sichuan University Press.

[2] Cao, Shunqing, eds. (2002). On Comparative Literature. Chengdu: Sichuan Education Press.

[3] Cao, Shunqing \& Zhuang, Peina. (2014). On Research and Application of Variation Theory of Comparative Literature in China. Cross-cultural Communication. 10 (4), 51-57.

[4] Dong, Ming. (2006). Translation: Creative Treason. Beijing: Central Compilation and Translation Press.

[5] Escarpit, Robert. (1987). Literary Sociology. Hefei: Anhui Literature and Art Publishing House.

[6] Huang, Mingzhuang. (2013). Treason, the Name, and Translating, the Nature-Analyzing Creative Treason in Translation. Journal of Jimei University. 16(2), 88-92.

[7] Liu, Xiaogang. (2006). Creative Treason from the Perspective of Hermeneutics. Comparative Literature in China. 62(1), 129-140.

[8] Lin, Zhang. (2000). On Yanfu's Faithfulness, Expressiveness and Elegance. Chinese Science and Technology Translators Journal. 13(4), 1-3.

[9] Lv, Jun. (2001). Course on English to Chinese Translation. Shanghai: Shanghai Foreign Language Education Press.

[10] Ni, Liangkang. (2004). On the Embarrassment of a Translator. Du Shu. 11: 90-97.

[11] Newmark, Peter. (2001). Approaches to Translation. Shanghai: Shanghai Foreign Language Education Press.

[12] Wang, Kefei. (1997). On the Cultural History of Translation. Shanghai: Shanghai Foreign Language Education Press.

[13] Wang, Zuoliang. (1989). Translation: Experiments and Reflections. Beijing: Foreign Language Teaching and Research Press.

[14] Xie, Tianzhen. (2012). Creative Treason: Discussion, Essence and Significance. Comparative Literature in China. 87(2), 33-40. 
[15] Yan, Fu. (1984). Preface to Translation of Evolution and Ethics. In Editing Board of Translation Newsletter, Translators Association of China (Eds.), Collection of Papers on Translation Studies (1894-1948). Beijing: Foreign Language Teaching and Research Press, 6.

[16] Ye, Jiaying. (1997). Wang Guowei and His Literary Criticism. Hebei: Hebei Education Press.

[17] Yue, Daiyun. (1995). Unicorn and Dragon-In search of Misreading in the universality among Eastern and Western Culture. Beijing: Peking University Press.

[18] Zhou, Yukai. (2003). Research on the Ancient Chinese Hermeneutics. Shanghai: Shanghai People Press.

[19] Zhao, Yanchun. (2005). Reductionism Method toward Translation. The Journal of English Studies. 3(2), 38-44.

Peina Zhuang is a lecturer in Foreign Language Department, Yinxing Hospitality Management College of CUIT and also a Ph.D candidate majoring in World Literature and Comparative Literature in College of Literature and Journalism in Sichuan University. Her areas of interests in research include comparative literature, cross-cultural studies and translation studies. She has published about ten papers in these fields. 